\title{
Seismic Analysis of Concrete Dam by Using Finite Element Method
}

\author{
Ismail Rozaina ${ }^{1,2^{*}}$, Kamsani Muhamad Hilfi ${ }^{2}$, and Mohd Nadzri Nur Insyirah ${ }^{2}$ \\ ${ }^{1}$ Institute for Infrastructure Engineering and Sustainable Management (IIESM), Universiti Teknologi \\ MARA, 40450 Shah Alam, Selangor, Malaysia \\ ${ }^{2}$ Faculty of Civil Engineering, Universiti Teknologi MARA, 40450 Shah Alam, Selangor, Malaysia
}

\begin{abstract}
This paper reports a brief study on linear seismic analysis of Sg. Kinta Concrete Dam. The analysis was conducted in order to determine the performance and behaviour of the dam under seismic excitation. The dam was modelled as two-dimensional and developed based on the design drawing that is obtained from Angkasa Consulting Services Sdn. Bhd. The seismic analysis of the dam is conducted using finite element analysis software package LUSAS 14.3 and the dam has been analyse as a plain stress problem with a linear consideration. A set of historic data, with E1 Centro earthquake acceleration of about $0.50 \mathrm{~g}$ is used as an earthquake excitation. The natural frequency and mode shape up to fifth mode of the dam has been obtained from the analysis to show the differences of the stress and deformation between each mode. The maximum horizontal and vertical stress of Sg. Kinta dam was found and the distribution of them was discussed in form of contours. The deformation of the dam were also been discussed by comparing the maximum displacement for each mode shaped.
\end{abstract}

\section{Introduction}

Dam is a structure that acts as a barrier to hold water or retain the water. Generally, dam has been built since many years ago and there are more than 45000 dams around the world. One of the countries that have lots of dam structure is China with over 22000 of large dams. Most of the dams were built for the irrigation purposes and almost all the large dams were used to produce electricity. There are many dams purpose other than produce electricity such as flood control, supply water to the cities, and river navigation. There are also dams that are built to serve multipurpose providing two or more benefits at once. The Sg. Kinta Dam was operated in August 2007 for the purpose of water supply and it was the first dam that used Roller Compacted Concrete (RCC) Technology in Malaysia. The dam reservoir has 29.9 million $\mathrm{m}^{3}$ storage to supply 227 million litre of water per day (mld) to a new treatment plant and 85 mld to the existing Ulu Kinta treatment plant. The dam is constructed with a height of $85 \mathrm{~m}, 760 \mathrm{~m}$ long and $70 \mathrm{~m}$ wide. Sg. Kinta Dam able to provide 639 million litres of water per day to Kinta Valley area.Though, Perak Water Board (LAP) is planning to use Sg. Kinta Dam as electricity generator with the agreement of Tenaga Nasional Berhad (TNB) in their future plan. The finite element method is an approximate

*Corresponding author: rozaina_fka_uitm@yahoo.com 
analysis technique which is basically consists of dividing a structure into a number of parts called elements [1]. Lee et al. [2] and Taghizadeh et al. [3] also adopted finite element method to study the performance of their structure as well. This method consists of assuming the continuous function for the solution and obtaining the parameters of the functions in a manner that reduces the error in the solution [4].Norshariza [1] stated that the finite element method is an approximately analysis technique which basically consists of dividing a structure into a number of parts called elements. Each node may have one or more degree of freedom which is defined as independent displacements used to describe the movement of each node. The number and type of elements should be selected so that the deformed shaped of the structure can be effectively represented. Deformations within the elements are assumed to follow predefined functions known as shape functions. The finite element method is the best method used in analysing the internal forces of elements by solving differential equation obtained through their discretization in space dimensions [5].

The most important step in finite element analysis of structure is creating mathematical modelling composed of separated elements which stimulate the real continuous structure. The purpose of this modelling is having a system with limited degree of freedom instead of system infinite degree of freedom [6]. In dam engineering, the finite element analysis is often used to model the physical behaviour of an existing concrete dam. When analysis is completed and results are obtained, large stress tensor fields must be manipulated to recuperate essential engineering quantities: the force and moment resultants acting on various user-defined surfaces [7]. Bathe [8] claimed that finite element method is a numerical method that can be used to solve different kinds of engineering problem in the stable, transient, liner or non-linear cases. De Salvo and Swanson [9] stated that by using the programs with interactive graphical facilities, it is possible to generate finite element models of complex structures with considerable ease and to obtain the results in a convenient, readily assimilated form.

Earthquake is a movement of earth crust which formed along faults and ruptures.Earthquake can be recorded using an instrument called as seismometer. Richter scale is used to represent magnitude of earthquakes. The effects of earthquake can be very severe and can cause major property damage [10]. Braile [11] states that there are four types of seismic wave namely Primary waves (P-waves), Secondary waves (S-waves), Love waves and Rayleigh waves. Seismic design and evaluation is most often based on linerelastic response-spectrum or time-history analysis procedures, although nonlinear analysis procedures can be used for evaluation of certain nonlinear mechanisms [12]. The equation of displacement of dynamic analysis of dam with $\mathrm{n}$ degree of freedom are as follow:

$$
M \ddot{U}+C \ddot{U}+K U=F(t)
$$

If the displacement is occurred with empty reservoir, the equation of dynamic displacement of dam can be written as:

$$
M \ddot{U}+C \dot{r}+K r=F(t)
$$

The absolute and relative displacement of dam nods equation can be shown as:

$$
U=r+j . U_{g}(t)
$$

The result of substitution of equation (2) and (3) is: 


$$
M \ddot{r}+C \dot{r}+K r=-\mathrm{M} \cdot j \cdot \ddot{U}_{g}(t)
$$

The $M, C$ and $K$ are Mass, damping and stiffness matrix respectively and $\dot{r}$ is applied earthquake acceleration and $r$ is the relative displacement of the nodes [13].

Time history is a set of graphical data that shows the intensity of the earthquake and contains acceleration, $g$ of the earthquake event [14]. Seismic analysis of the dam or structure required the time history data. There are several methods exist to input seismic excitation when making the seismic time-history analysis for design: 1) to input the displacement time-history at the base, which is called displacement method; 2) to input the inertia loading calculated from the time-history of support motion acceleration, which is called acceleration method; 3) large mass method [15]. For use in linear dynamic analysis, at least three time-histories (for each component of motion) should be used for each design earthquake. The two basic methods that are commonly used for the seismic dynamic analysis are time-history and response spectrum methods. Naibin J. et al. [15] states that the time-history method is relatively consumed more time, costly and lengthy. On the other hand, the response spectrum method is relatively more rapid, concise, and economical. However, time-history method must be employed when geometrical and/or material nonlinearities are present in the structural systems. Nowadays, it is more convenient for using time-history method than before for advancing of computer's hardware and software.

Many researchers Major [16], Schoeber [17], Polyakov [18] and Wyatt [19] stated that earthquake or seismic loads are the major dynamic loads being considered in the analysis and design of dams especially in earthquake prone areas. They are of kinematic origin and owe their existence to vibration caused in the structure by the movement of the earth's surface during an earthquake. They have random characteristics and are regarded as deterministic in practical calculations to simplify the design model [16-20]. Parish et al. [19] shows the deformation of the dam by applying dynamic loading at the base of the foundation layer as a velocity excitation.

\section{Research background}

This study involved the modelling of Sg. Kinta Concrete Dam located at $12 \mathrm{~km}$ north east of Ipoh which part of the Greater Ipoh Water Supply Scheme Phase 2. The study comprised of several tasks in finite element modelling and involves a modelling technique for dynamic analysis using a computer program. This research starts with obtaining and understanding the literature review concerned with the related research topic followed by collection of the dam data, understanding the finite element using LUSAS 14.3, building and analyse a model by developing a two dimensions finite element model with the LUSAS 14.3 and finally obtains the result and conclusion based on the analysis.

Sg. Kinta Dam was operated in August 2007 for the purpose of water supply and it was the first dam that used Roller Compacted Concrete (RCC) Technology in Malaysia. The dam is straight axis gravity structure with vertical upstream face and a uniform downstream face at 0.75 in horizontal and 1.0 in vertical from the crest. Figure 1 shows the typical cross section of Sg. Kinta Dam. The material used for RCC is fly ash as replacement of cement to reduce cost, heat of hydration, to increase workability and have long term strength development.

The dam reservoir has 29.9 million $\mathrm{m}^{3}$ storage to supply 227 million litre of water per day (mld) to a new treatment plant and 85 mld to existing Ulu Kinta treatment plant. The dam is constructed with a height of $85 \mathrm{~m}, 760 \mathrm{~m}$ long and $70 \mathrm{~m}$ wide. Sg. Kinta Dam able to provide 639 million litres of water per day to Kinta Valley area. However, Perak Water 
Board (LAP) is planning to use Sg. Kinta Dam as electricity generator with the agreement of Tenaga Nasional Berhad (TNB) in their future plan.

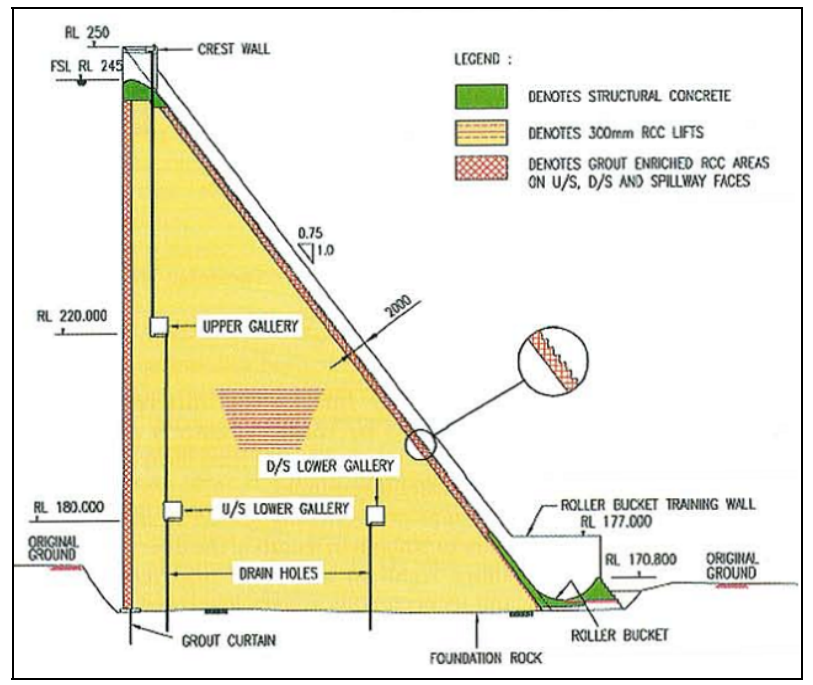

Fig. 1. Typical cross section of Sg. Kinta Dam [21].

\section{Modal analysis}

The main dynamic analysis is performed by using a modal approach or analysis due to the weight of the dam and horizontal component of the ground motion. The seismic excitation that has been used in the analysis is obtained from the E1 Centro time history data and presented in Fig 2.

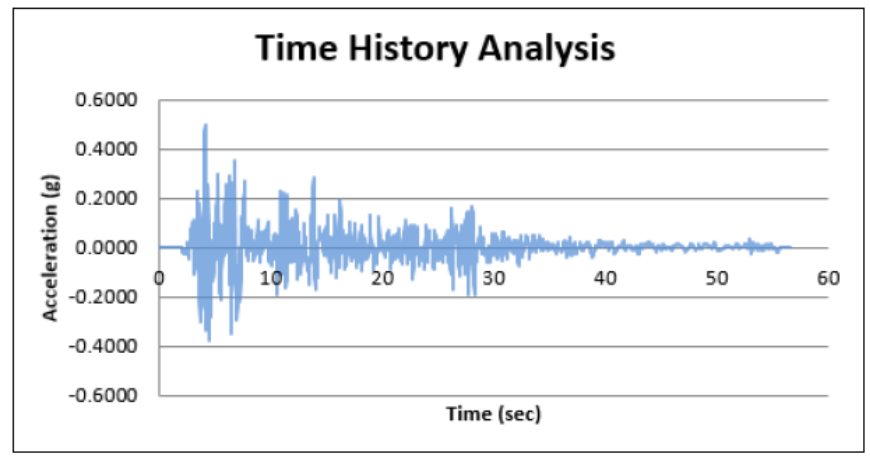

Fig. 2. Time history analysis of E1 centro earthquake [21].

The result obtained from Modal Analysis is the natural frequency and the mode shape of Sg. Kinta Dam under certain seismic excitation or loading. There is no limitation to the mode shape of the dam, but in this study, there are only five different mode shapes of the dam is presented with different natural frequency each. The purpose is just to show the dam deformation under the seismic excitation. Mode shape shows the specific pattern of vibration at a specific frequency at specific period of time. Table 1 shows different mode shape with different period of time. 
Table 1. No. of mode shape associate with period.

\begin{tabular}{|c|c|}
\hline No. of Mode Shape & Period (sec.) \\
\hline 1 & 0.32 \\
\hline 2 & 0.24 \\
\hline 3 & 0.17 \\
\hline 4 & 0.16 \\
\hline 5 & 0.13 \\
\hline
\end{tabular}

It is noticed that different mode shape will be associated different frequency. It shows that the period of time is decreased from 0.32 to 0.13 from the mode shape 1 to mode shape 5. There is only a slightly difference in the natural frequency for each mode. This will makes the mode shape or the deformation of the dam change too little for each frequency and will be difficult to see the comparison between each shape.

\section{Deformation analysis}

The deformation level of each dam occurs due to the assignation of the dynamic loading during the analysis. It can be seen that the deformation of the dam are significantly to the horizontal direction with different displacement each. Fig. 3 shows mode shape 5 with $3.48 \mathrm{~mm}$ of maximum displacement due to seismic excitation.

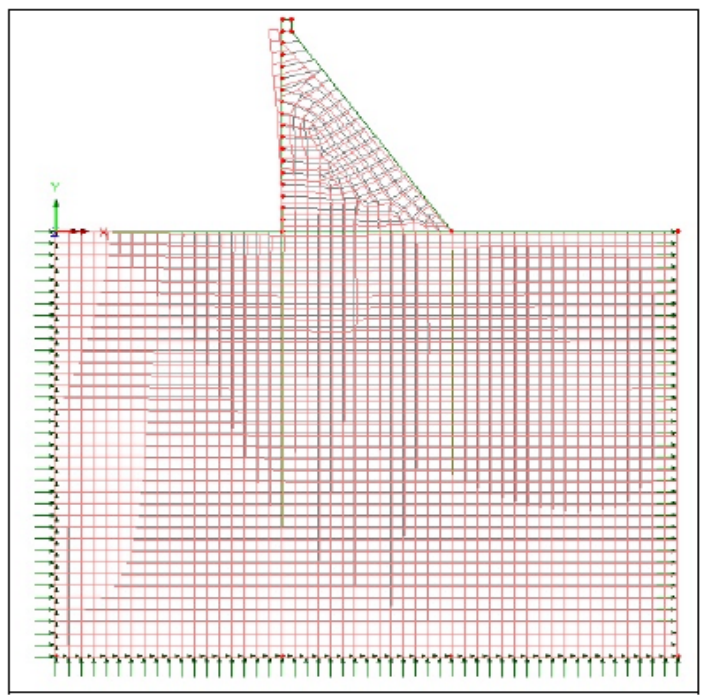

Fig. 3. Mode Shape 5 (Max. displacement $=3.48 \mathrm{~mm})$.

\section{Stress analysis}

The dynamic analysis shows the stress in the dam structures when subjected to the dynamic loading. The purpose of this stress analysis is to determine whether the dam can safely withstand the specified forces. Table 2 shows the normal stress and shear stress of the dam due to the seismic excitation. 
Table 2. Maximum normal stress and shear stress.

\begin{tabular}{|c|c|c|}
\hline No. of Mode Shape & $\begin{array}{c}\text { Normal Stress } \\
\left(\mathrm{kN} / \mathrm{m}^{2}\right)\end{array}$ & $\begin{array}{c}\text { Shear } \\
\left.\text { StresskN } / \mathrm{m}^{2}\right)\end{array}$ \\
\hline 1 & 194.120 & 109.008 \\
\hline 2 & 341.909 & 221.248 \\
\hline 3 & 199.523 & 97.123 \\
\hline 4 & 2.29304 & 3.66383 \\
\hline 5 & 436.699 & 87.1719 \\
\hline
\end{tabular}

The stress of the dam is shown in contours in order to visualize the distribution of the stress. Fig. 4 to Fig. 7 shows the normal and shear stress contours for mode shape 1 and 5 respectively. Fig. 4 shows the maximum stress about $194.12 \mathrm{kN} / \mathrm{m}^{2}$ at node 1222 and $108.8666 \mathrm{kN} / \mathrm{m}^{2}$ of minimum stress at node 2 under dynamic loading. $436.699 \mathrm{kN} / \mathrm{m}^{2}$ of maximum stress at node 1 and $-294.538 \mathrm{kN} / \mathrm{m}^{2}$ at node 2 was shown in Fig. 5.

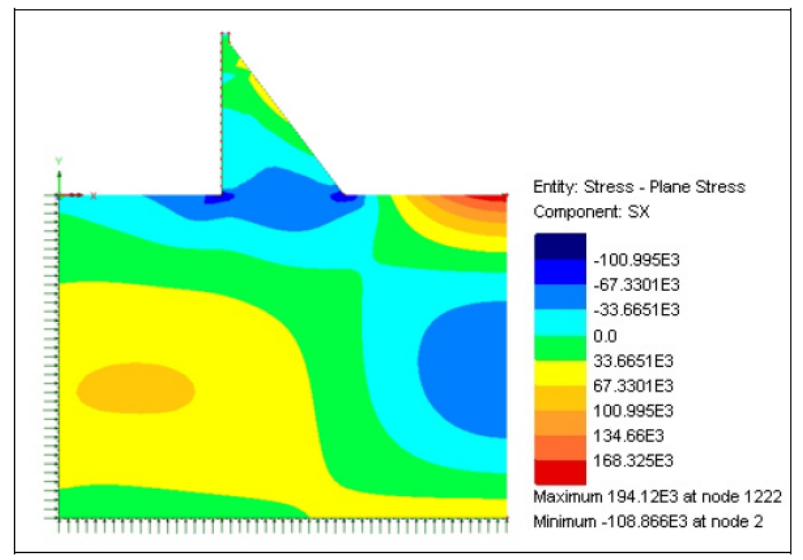

Fig. 4. Mode shape $1\left(\right.$ Normal Stress $\left.=194.12 \mathrm{kN} / \mathrm{m}^{2}\right)$.



Fig. 5. Mode shape $5\left(\right.$ Normal Stress $\left.=436.699 \mathrm{kN} / \mathrm{m}^{2}\right)$. 
Fig. 6 shows the maximum stress about $109.008 \mathrm{kN} / \mathrm{m}^{2}$ at node 1272 and $-121.955 \mathrm{kN} / \mathrm{m}^{2}$ of minimum stress at node 1919 under dynamic loading. $87.1719 \mathrm{kN} / \mathrm{m}^{2}$ of maximum stress at node 1896 and $-535.707 \mathrm{kN} / \mathrm{m}^{2}$ at node 1927 was shown in Fig. 7.

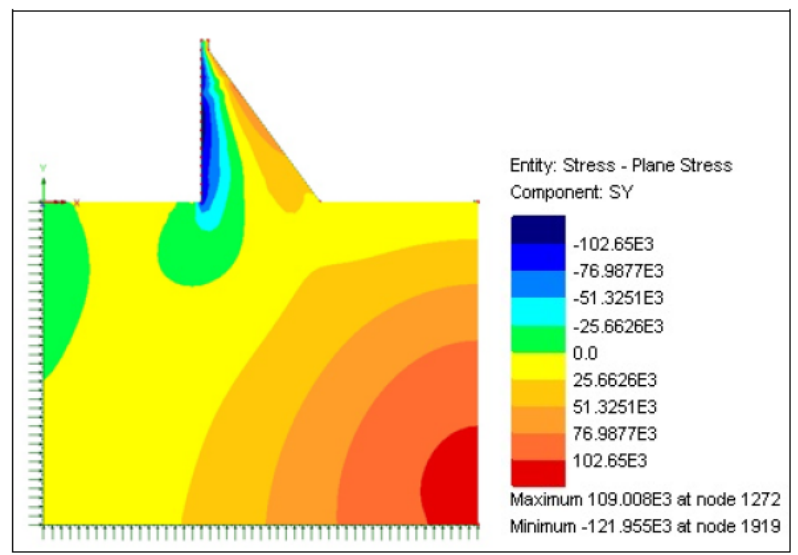

Fig. 6. Mode shape 1 (Shear Stress $\left.=109.008 \mathrm{kN} / \mathrm{m}^{2}\right)$.

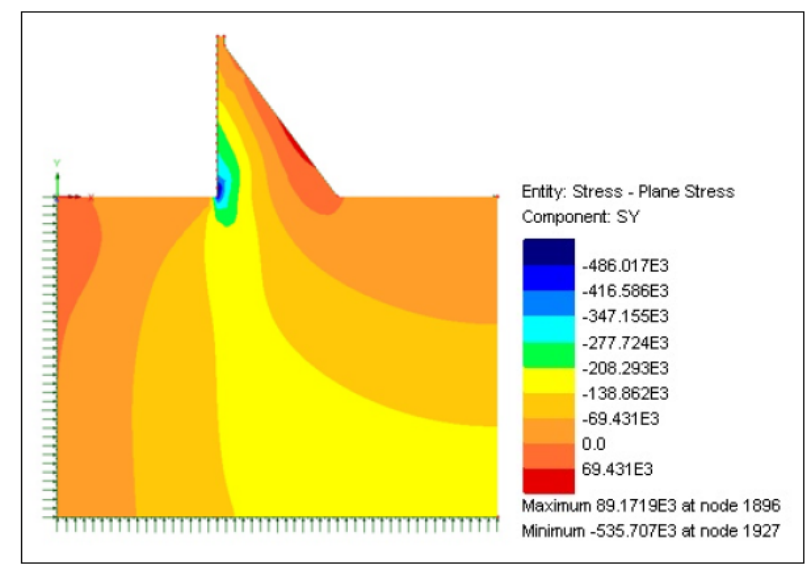

Fig. 7. Mode shape 5 (Shear Stress $\left.=87.1719 \mathrm{kN} / \mathrm{m}^{2}\right)$.

It is noticed that for each mode shape there are different in the maximum and minimum stress. It is due to the variable of the time history data which is the acceleration of the earthquake. The maximum stresses obtained from the analysis need to be compared with the material allowable capacity in order to determine whether the stress exerted on the dam can with stand the seismic loading. The stress allowable capacity of concrete was around $800 \mathrm{kN} / \mathrm{m}^{2}$ as shown in Table 3 .

Table 3. Allowable capacity.

\begin{tabular}{|c|c|c|}
\hline $\begin{array}{c}\text { Normal Stress } \\
\text { (Max.) }\end{array}$ & $\begin{array}{c}\text { Shear Stress } \\
\text { (Max.) }\end{array}$ & $\begin{array}{c}\text { Allowable } \\
\text { Capacity }\end{array}$ \\
\hline $221.248 \mathrm{kN} / \mathrm{m}^{2}$ & $436.699 \mathrm{kN} / \mathrm{m}^{2}$ & $800 \mathrm{kN} / \mathrm{m}^{2}$ \\
\hline
\end{tabular}


It can be seen that the normal stress and shear stress exerted by the dam does not exceeded the allowable capacity of the material.

\section{Conclusion}

An earthquake analysis of concrete dam, which is referred to as modal analysis and stress analysis has been used in order to find the performance and the behaviour of the dam. The method has been described previously, and the procedure is implemented in a computer program LUSAS 14.3. The analysis of the concrete dam which is Sg. Kinta Dam is considered as linear dynamic analysis and is carried out by utilizing 5 modes of shape for the dam. Based on the dynamic analysis, the performance of the dam can be considered as a satisfactory result due to the acceptable maximum displacement value which is $3.48 \mathrm{~mm}$ in the mode shape 5. The stress behaviour of the dam was also satisfactorily acceptable because the dam normal and shear stress which is $221.248 \mathrm{kN} / \mathrm{m}^{2}$ and $436.499 \mathrm{kN} / \mathrm{m}^{2}$ respectively does not exceed the allowable stress capacity which is $800 \mathrm{kN} / \mathrm{m}^{2}$. The result obtained from the linear dynamic analysis conducted in this project was also shown that LUSAS 14.3 software was capable in analysing the seismic response.

The authors would like to acknowledge that this research has been carried out as part of a project Science Fund with File No: 100-RMI/SF 16/6/2 (3/2015) funded by Ministry of Science, Technology and Innovation (MOSTI) and support from Faculty of Civil Engineering, Universiti Teknologi MARA (UiTM).

\section{References}

[1] M.B. Norshariza, Modal analysis of concrete bridge decks subjected to free vibration, Master of Engineering Thesis, Faculty of Civil Engineering, Universiti Teknologi Malaysia, (2005)

[2] J.E. Lee, J.B. Kim, K. Park, Finite element analysis for improvement of folding defects in the forging process of subminiature screws, J. of the Korean Society for Precision Engineering, 32(6), 509-515 (2015)

[3] M. Taghizadeh, H.R. Ovesy and S.A.M. Ghannadpour, Nonlocal integral elasticity analysis of beam bending by using finite element method, Structural Engineering and Mechanics, 54(4), 755-769 (2015)

[4] U.S. Dixit, Finite element method: An introduction, department of mechanical engineering, Indian Institute of Technology Guwahati-781, 39 (2008)

[5] A.A. Adedeji, Seismic analysis of earth wall gravity dam using decoupled modal approach, Int. Egyptian e-Journal of Engineering and Mathematics: Theory and Application, 5, 19-34 (2008)

[6] M.A.L. Yanghin and M.A. Hesari, Dynamic analysis of the arch concrete dam under earthquake force with ABAQUS, J. of Applied Sciences, 8(15), 2648-2658 (2008)

[7] P. McLean, P. Léger and R. Tinawi, Post-processing of finite element stress fields using dual kriging based method for structural analysis of concrete dams, Finite Elements in Analysis and Design, 42(6), 532-546 (2006)

[8] K.J. Bathe, Finite Element Procedures, $1^{\text {st }}$ ed., Prentice Hall Inc., Englewood Cliffs, New Jersey, 735, (1996)

[9] G.J. De Salvo and J.A. Swanson, ANSYS: Engineering analysis system: User manual, Swanson Analysis System, (1986)

[10]D. Hyndman, Natural Hazards and Disasters, $2^{\text {nd }}$ ed., Brooks.Cole, USA, (2008)

[11]L. Braile, Seismic waves demonstration and animations, Purdue University, 1-15, (2010) 
[12]Y. Ghanaat and A.K. Chudgar, Seismic design and evaluation of concrete dam - An Engineering Manual, (2007)

[13]O.C. Zienkiewicz and R.L. Taylor, The finite element method, $5^{\text {th }}$ ed., ButterworthHeinenmann, Oxford, UK, (2000)

[14]K.S. K.Sulaiman, Seismic vulnerability of smart tunnel, Universiti Teknologi Malaysia, (2008)

[15]J. Naibin, M. Qing and Z. Yixiong, Research on time-history input methodology of seismic analysis, (2007)

[16]A. Major, Dynamics in civil engineering, $2^{\text {nd }}$ ed., Collet's Holding Ltd, London, (1980)

[17]W. Schoeber, Regarding the load bearing behaviour of large dams, Die Wasserwirstchaft, 71(81/1287), (1981)

[18] S.V. Polyakov, Design of earthquake resistant structures basic theory of seismic stability, $2^{\text {nd }}$ ed., Mir Publishers (1985)

[19] Y. Parish and F. Najaei Abadi, Dynamic behaviour of earth dam for variation of earth material stifness, Int. J. of Applied Science, Engineering Technology, 50, 606-611, (2009)

[20] Y. Ghanaat and B.J. Rasmussen, Evaluation of seismic stability of claytor dam using linear and nonlinear time history analysis, (2005)

[21]K. Muhamad Hilfi, Seismic analysis of a concrete dam by using finite element method: A case study of Sungai Kinta dam, Bachelor of Engineering Thesis, Universiti Teknologi MARA, (2010) 